\title{
A quem se destina o projeto: Reflexões da inclusão social aplicadas ao Design.
}

For who is the project: Reflections about social inclusion applied to Design

MARTINS, Elisa Batista Conrado; Graduada; Universidade do Estado do Pará

elisabatistacm@gmail.com

SANTOS, Luciana Guimarães Teixeira; Mestre; Universidade do Estado do Pará

lucianaguimaraes@uepa.br

\section{Resumo}

O design é uma disciplina que se propõe a solucionar problemas, logo, pensar a quem o projeto se destina deve ser o ponto de partida. Contudo, nota-se que ainda ocorre a idealização do usuário "padrão" que é muitas vezes utilizado como base para o desenvolvimento de produtos e ambientes, influenciando não apenas no uso do produto em si, mas nas relações sociais de uma parcela da população que não se encaixa em tal "normalidade". O presente artigo busca contribuir para reflexões acerca das consequências que um resultado de projeto de design pode trazer quando não pensado de forma inclusiva; buscando também dissertar sobre a compreensão errônea do termo "inclusão" quando equiparado a "integração" e suas consequências. A pesquisa culmina na explanação dos principais obstáculos enfrentados na implantação do design inclusivo, como por exemplo, o preconceito relacionado a certos termos empregados, além da deturpação que ocorre a certos objetivos da área em questão.

Palavras Chave: Design Inclusivo; Diversidade; Preconceito.

\begin{abstract}
Design is a discipline that proposes to solve problems, so the designer must think to whom the project is intended. There is still a "standard" user idealization that is often used as basis for the development of products and environments, influencing not only the use of the product itself, but also the social relations of a part of the population that does not fits in this "standard". The present article aims to open up reflections about the consequences that a design project result can bring when isn't thought in an inclusive way; also to discuss the misunderstanding of the term "inclusion" when assimilated to "integration" and the consequences that this can cause. The research culminates in the explanation of the main obstacles faced in the implantation of the inclusive design, for example, the prejudice related to certain terms employed, as well as the misrepresentation of certain objectives of the area in question.
\end{abstract}

Keywords: Inclusive Design; Diversity; Prejudice. 


\section{Introdução}

A falta de uma rampa em uma calçada, ausência de um corrimão, um piso desnivelado, uma entrada estreita, a área de circulação de um recinto tortuosa; entre outras questões, são situações eventuais que causam certo desconforto até mesmo para pessoas que não possuem nenhum tipo de limitação física ou cognitiva. Um desconforto, talvez confusão e tendência ao erro que logo se repara, no entanto, quando isso recai para a situação de exclusão e limitação da atividade plena que é garantido por lei a todos os cidadãos, encontra-se aqui um problema sério de projeto que não foi considerado para todos aqueles que viessem a utilizar o produto e/ou ambiente. Imaginar-se "do outro lado" é um bom começo para se perceber a relevância da inclusão e como seus conceitos e percepções são de suma importância no momento que se pensa um projeto de design. Dessa forma, é preciso se questionar: A quem se destinará o projeto? A concepção deve partir do usuário para com o projeto ou o inverso? A ideia central da presente pesquisa é salientar que toda metodologia e resultado de um projeto de design deve servir de ferramenta para promover o sentimento de bem-estar além de, da melhor maneira possível, se aproximar dos sentimentos de liberdade e independência desses que virão a usar os ambientes/produtos inclusivos, para isso, é pertinente se ter conhecimento do significado dos termos e se aprofundar nos modos de trabalhá-los de forma a evitar equívoca e má interpretação do que seria de fato a inclusão e, dessa forma, alcança-la através do design inclusivo.

\section{Segregação, Integração e Inclusão}

Ao discutir a questão da inclusão social aliada ao design de forma geral, é necessário ter uma visão macro antes de qualquer abordagem. Entender quais os conceitos que permeiam tal processo para evitar confusões, no que concerne na epistemologia dos termos, questões como a integração x inclusão; bem como a linha tênue entre tais conceitos e o de segregação. A partir disso surge o questionamento: Como podem ser trabalhados tais pontos no momento que se propõem um projeto de design?

É de suma importância começar a explanar acerca do assunto fazendo um breve apanhado no que historicamente foi a primeira proposta de integração escolar, elaborada em 1972, na Educação Especial, por profissionais Escandinavos, no qual denominaram de princípio da normalização. De forma geral, este se pautava em proporcionar as pessoas com alguma deficiência a garantia de usufruir de seu direito de viver de forma mais "normal" possível no ambiente social. E como menciona Batista e Enumo (2004), tem-se aqui como "normal" não o processo de tornar isso algo comum, mas sim proporcionar a pessoa oportunidades, de forma a garantir seu direito de ser diferente e ter suas necessidades compreendidas e atendidas pela sociedade. Com isso se parte para o conceito de integração, sendo este uma consequência dos princípios fundamentais dessa normalização, pois: "Normalização é o objetivo. Integração é processo" (PEREIRA, 1990 apud BATISTA; ENUMO, 2004, p. 1).

Seguindo essa abordagem que se mostrou bastante promissora, nasce no Brasil um modelo de educação especial, fazendo desse acompanhamento para com pessoas com deficiência algo mais específico e centrado especialmente nele, com isso, tal modelo acabou por contribuir com a segregação, pois separá-los dos demais não é encarado como o melhor caminho para se alcançar a 
inclusão, pois é através desse contato em sociedade e nas interações sociais que é possível se compreender as diferenças e as aceitar de forma respeitosa (BUENO, 1991; GLAT, 1989 apud BATISTA e ENUMO, 2004). Dessa forma, entende-se como inclusão a inserção total do indivíduo em convivência com o meio externo, sendo bem: ampla, total e incondicional.

Em contrapartida, o conceito que permeia a integração é mais parcial, sua inserção está condicionada as possibilidades de cada pessoa. Nela se acredita que a deficiência está no indivíduo, sendo estes cuidados incorporados no processo sempre que preciso para que haja essa participação nas relações sociais ou atividades diárias e aprendizagem, dentro de suas limitações. De forma geral, a inclusão busca uma mudança mais a fundo, de comportamento tanto da sociedade, como do modo de pensar nesses processos, sempre se adaptando as necessidades desses usuários; ela não quer a mudança pontual, mas sim ampla, visando não a singularidade, mas sim a diversidade e coletividade de percepções.

É notório que o Brasil ainda apresenta uma carência na abordagem da inclusão no ensino, focando aqui especificamente no design inclusivo como elemento da matriz curricular dos cursos de design pelo país. Infelizmente, acredita-se que um dos grandes entraves se encontra na falta de compreensão do real objetivo dessa perspectiva de projeto; que se trata de incluir de forma plena, não segregar, mas sim atender a todos que utilizarão sem tratar especialmente cada caso de forma isolada. Inclusão é pensar nas unidades de forma a atender o todo, como menciona Simões e Bispo (2006), é partindo do princípio que as pessoas são todas únicas com diferentes habilidades e não são essas diferenças que condicionarão a participação delas na convivência com o meio em sociedade, mas sim os ambientes e produtos que devem buscar entender para corresponder a tais necessidades e capacidades.

\section{Design Inclusivo}

O Design é uma área de conhecimento que tem como objetivo atender demandas da sociedade, mas ao descrever o perfil de clientes que os designers e arquitetos estão habituados a trabalhar Simões e Bispo $(2006$, p. 8) pontuam como um mítico homem médio que é jovem, de estatura média e que não se cansa e nem se engana, mas que não existe de fato. Ainda assim os autores confrontam essa discussão colocando o conceito do Design Inclusivo como uma nova perspectiva desse perfil que irá englobar um maior número de usuários, ou seja, esta área de conhecimento busca acima de tudo permitir a utilização dos produtos e/ou ambientes por pessoas de todas as capacidades, sejam elas com limitadores físicos, mentais, psicológicos, permanentes ou temporários, contribuindo assim, por meio do pensar dos projetos, a não discriminação e inclusão social das pessoas assegurando nada mais do que seu direito garantido por lei: de viver plenamente em sociedade.

Simões e Bispo (2006) continuam com a colocação apontando uma comum confusão que o Design Inclusivo acaba por causar: a de tratar-se de um desenvolvimento de soluções específicas como se fosse seu único objetivo. Neste segmento do design existe de fato o envolvimento com pessoas com deficiência, mas no sentido de encarar a situação como um caminho de garantia de adequação para uma faixa maior da população, tendo como base pessoas nessa condição como parâmetro para ter maior garantia de atendimento aos demais.

Ainda que tratadas como minoria, a parcela da população que se enquadra em PCD (Pessoa 
com Deficiência) se mostra expressiva e necessita ser salientada. Segundo dados fornecidos pelo IBGE (2009), por volta de 14,5\% dos brasileiros possuem algum tipo de deficiência, cerca de 27,9 milhões de indivíduos compõe essa porcentagem, seja essa deficiência congênita ou provocada. Para uma visão mais ampla desses números é possível ver a divisão dos PCDs nas regiões do Brasil pela tabela 1.

Tabela 1 - Distribuição de PCDs por região no Brasil.

\begin{tabular}{ll}
\hline Região & $\%$ \\
\hline Nordeste & 40 \\
Norte & 14 \\
Sudeste & 12 \\
Sul & 18 \\
Centro-Oeste & 16 \\
\hline
\end{tabular}

Fonte: Organização Mundial da Saúde (2000)

Além da incidência de cada tipo no país na tabela 2 .

Tabela 2 - Incidência dos tipos de deficiência na população brasileira.

\begin{tabular}{ll}
\hline Tipos de deficiência & $\%$ \\
\hline Mental & 50 \\
Física & 20 \\
Auditiva & 15 \\
Visual & 5 \\
Múltipla & 10 \\
\hline
\end{tabular}

Fonte: Organização Mundial da Saúde (2000)

Além das categoriais das condições humanas citadas na tabela 2, também se pode citar a mobilidade condicionada que, segundo a NBR 14022 (2011), trata se dos indivíduos que não se enquadram no conceito de pessoa com deficiência mas tenha, por algum motivo, dificuldade de se locomover de forma permanente ou temporariamente comprometendo fatores como: redução efetiva de mobilidade, flexibilidade, coordenação motora e percepção. Tais caraterísticas abrangem indivíduos como: idosos, gestantes, obesos e pessoas com criança de colo; sendo estas também contempladas no momento que se pensa em um projeto inclusivo.

É importante ter em mente que o design inclusivo vai muito além de "algo a mais" em um projeto, este se faz necessário e deve ser aplicado como fator básico, pois se esta área de conhecimento se propõe a dar soluções, que seja de forma democrática para todos aqueles que virão a ter a necessidade básica de utilizá-lo, ou o mais próximo possível disso. Cambiaghi (2012) 
explana acerca dessa questão ao pontuar a evolução do conceito de "desenho livre" para o de "desenho universal" que foi adotado inicialmente nos Estados Unidos, este passou a se tratar por universal pelo fato de se destinar a qualquer pessoa, e por ser fundamental para a realização de ações essenciais da vida cotidiana. Atualmente pode-se dizer que esse conceito evolui novamente para o Design Inclusivo com a consolidação dos pressupostos dos direitos humanos, dessa maneira, se trata de um conceito que transcende a responsabilidade social do profissional que propõe um projeto que virá a ser utilizado por indivíduos.

É indiscutível que um produto ideal que atende a necessidade de todas as pessoas é uma utopia, no entanto, é importante levar esse ideal como estímulo para desenvolver cada vez mais projetos que abranjam uma maior gama dessa população. Entende-se aqui, que o design inclusivo não se trata de uma prática para pessoas com deficiência, mas sim para a diversidade, não é segregar, mas sim integrar e incluir. Cambiaghi (2012) abre uma reflexão pontuando uma questão que, segundo a autora, cabe a todos os profissionais envolvidos nas fases de projeto se questionarem: "Em que medida um projeto inclui e em que medida ele exclui o usuário?" (CAMBIAGHI, 2012, p. 16). A grande lógica é que se trata de um processo de entendimento para a realização de um bom projeto, não é a construção de um constrangimento, mas sim a universalidade de utilização num limite inatingível, mas que no momento em que é buscado promove o que se trata de um processo de melhoramento contínuo do mundo construído (SIMÕES e BISPO, 2006).

Segundo Cambiaghi (2012), as barreiras criadas pelo próprio homem, devido a falta de acessibilidade, acabam por fazer os indivíduos se indagarem acerca da condição de fazer certas ações por simplesmente estarem numa cadeira de rodas, quando a pergunta deveria ser com relação ao porquê desse projeto não ser adaptado para receber uma pessoa nessas condições. Se o homem que constrói esse ambiente em que vive, por que não o fazer de forma a incluir ao invés de excluir aqueles que, por alguma razão, possuem algum tipo de limitação física e/ou cognitiva? Ainda segundo a autora, é necessário que o ambiente se ajuste às necessidades do usuário se tornando assim mais confortável, visto que, quando ocorre o inverso e não é levado em conta essas questões, sejam elas as necessidades bem como as limitações humanas, este pode chegar a ser mais inóspito que o meio natural (CAMBIAGHI, 2012).

Dessa forma, a maior questão é saber diferenciar o que realmente é considerado detentor de incapacidade: o indivíduo que é incapaz de usufruir o ambiente plenamente ou o projeto que é incapaz de atendê-lo? A incapacidade ou limitação é algo condicionado a diversos fatores, em sua maioria ao meio externo e como ele foi pensado e construído.

\footnotetext{
Não se pode dizer, simplesmente, que um ser humano é ou não incapacitado. Esta situação só pode ser analisada se levada em consideração a atividade específica, as condições do ambiente e as ajudas técnicas. Pois o auxílio de ajudas técnicas incrementa as habilidades humanas e a eliminação de barreiras reduz as exigências do ambiente. Conclui-se que, encontrada uma situação com desempenho abaixo do normal, o correto seria dizer que o sistema humano + ajuda técnica + atividades + ambiente é deficiente e não apenas o elemento humano (BAPTISTA, 2011, p. 67-68).
}

Para auxiliar no desenvolvimento de projetos pautados no design inclusivo, é válido se apropriar dos princípios do design universal formulados por uma equipe do Centro para o Design Universal da Universidade Estadual da Carolina do Norte (EUA), , que estão contemplados no projeto "Estudos para Incrementar o Desenvolvimento do Design Universal"e e servem de auxílio no momento que se realiza umaavaliação de produtos de consumo, espaços arquitetônicos e 
elementos de construção, sendo os princípios: Uso equitativo; Flexibilidade de uso; Uso simples e Intuitivo; Informação Perceptível; Tolerância ao erro; Baixo esforço físico e; Tamanho e espaço para aproximação e uso (CARLETTO et al., 2008, p. 7-16). Estes buscam aproximar-se do ideal almejado, facilitar o uso e torná-lo mais acessível aos que têm algum tipo de limitação ou incapacidade para o desempenho de atividades básicas do cotidiano de um indivíduo que, de forma plena, goza de seus direitos garantidos pela constituição.

Contudo, por mais que haja a apropriação de vertentes do Design Universal, é importante salientar que ambas as áreas, apesar de apresentarem pontos em comum, tem suas diferenciações. De forma geral, o design inclusivo deve se apropriar de fatores que vão além do que o universal apresenta, como questões voltadas a: Usabilidade (com objetivo de qualificar através da quantificação de dados gerados pela interação com os produtos dentro de seu contexto de uso), Ergonomia (principalmente física e cognitiva) e o Design Centrado no Usuário (com a participação efetiva do usuário no momento do desenvolvimento do projeto); como demonstrado na figura 1.

Figura 1 - Representação do escopo do Design Inclusivo.

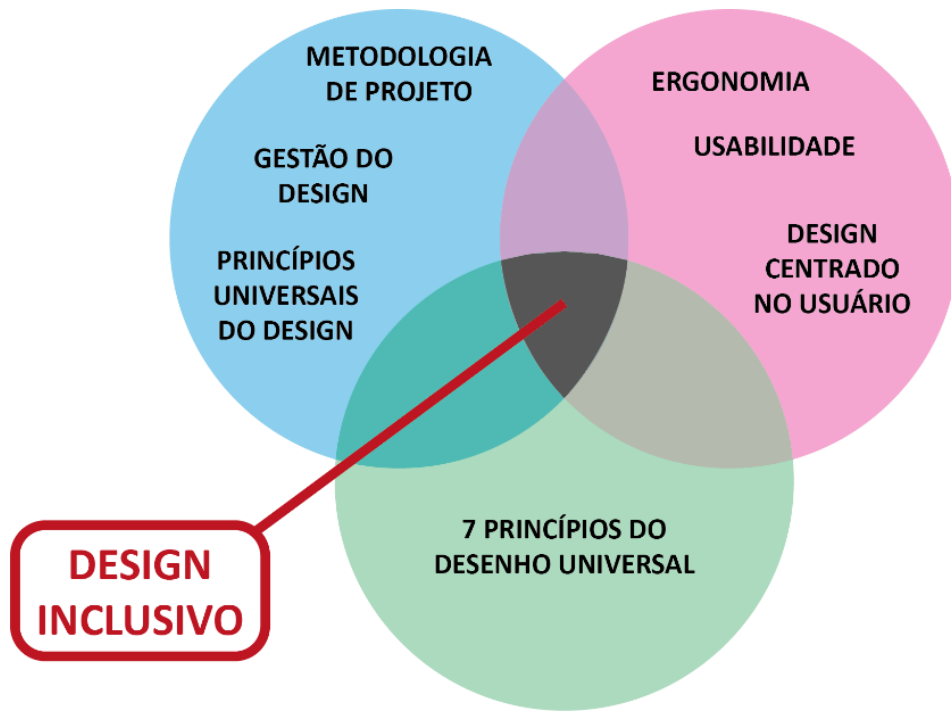

Fonte: Miranda; Silva e Okimoto (2012).

Segundo Simões e Bispo (2006), o design inclusivo trata-se de uma prática projetual democrática e respeito pelos direitos humanos, além de uma defesa pela igualdade de oportunidades, já que considera que essas barreiras são criadas pelos próprios homens, então se deve partir deles a atitude de tentar eliminá-las ou, pelo menos, tentar reduzi-las ao máximo; para Coleman (et al, 2011), é uma estratégia de design assim como o Design Emocional ou o Design Sustentável; entende-se aqui como uma metodologia que busca um ideal, sendo seu diferencial o destaque nas primeiras fases do processo projetual o compromisso em contemplar de forma efetiva amplos grupos de usuários em todos os seus aspectos (físico-cognitivo-sensoriais), evitando assim a necessidade de fazer adaptações posteriores, de forma que não haja gastos além do programado bem como constrangimentos futuros. Dessa forma, é importante, antes de tudo, conhecer profundamente as possíveis características físicas, sensoriais e cognitivas daqueles que não correspondem ao estereótipo daquele homem médio que os autores pontuaram como o perfil que comumente consideram ao trabalhar um projeto de design. 
Simões e Bispo (2006), ainda dissertam acerca do fato da necessidade dessa nova atitude, em que a dimensão social da prática de projeto esteja sempre presente, sendo esta alcançada através do questionamento que o próprio projetista deve fazer a si mesmo acerca da adequação do uso dos espaços ou produtos que virá a projetar. Se referindo aqui a grande influência do processo de concepção de um projeto, visto que a estratégia partindo da criação é muito mais efetiva e vantajosa, além de proporcionar maior garantia de satisfação durante seu uso nas atividades diárias.

\begin{abstract}
Em sua formulação, design universal engloba o processo em que soluções de acessibilidade teriam um apelo para aceitação mercadológica e uma absorção na vida cotidiana de um grande público. Devemos lembrar ainda que design tem vínculo com o termo português "desígnio", isto é, decisão a ser adotada numa sequência de tantas escolhas possíveis e compatíveis com o contexto em que o produto do design se destina (CORRÊA, 2009, p. 89).
\end{abstract}

Existe uma carência no que concerne em detalhamento no modo como as definições do desenho universal e design inclusivo atuam, questões como especificações e normas; o que gera certo incômodo para alguns profissionais que os utilizam como meio de alcançar certos padrões; no entanto, para Corrêa (2008) tal condição é mais benéfica do que prejudicial, visto que, para o autor, a rigidez, controle legal e a padronização normativa acabam por limitar mais do que incentivar a criatividade do profissional para desenvolver inovações. Contudo, Corrêa (2008) continua sua colocação justificando que tal condição de escassez de especificações não é algo intencional, isso se dá pela impossibilidade de que sejam definidos mecanismos objetivos e mensuráveis no âmbito legal para a inclusão irrestrita dos diferentes perfis de usuários fazendo classificações de tipos, por exemplo; o só contribuiria para a segregação, caminho totalmente contrário ao que o design inclusivo propõe.

A liberalização de iniciativas para consolidação de produtos de acessibilidade no mercado que facilitem a vida de todos, na verdade, só é possível caso seja abolido o raciocínio pela compartimentação do conhecimento em função de especificidades das deficiências dos usuários, como também, o preconceito e os danos que uma ou outra categorização das características dos usuários pode acarretar (CORRÊA, 2008, p. 90).

Com isso, é preciso se atentar, no momento que se propõe um projeto de inclusão dentro do design, para não cair na chamada "discriminação compensatória", termo usado por Corrêa (2008), como estratégia utilizada pelas normas que se voltam para pessoas com deficiência de modo a promover uma acessibilidade assistida. Para o design inclusivo não é separar os indivíduos devido suas condições, mas sim o uso do meio sem discriminação de forma acessível a todos; assim, não ter como guia único tais normas, mas sair dela a essência para alcançar a inclusão social nos ambientes e produtos construídos.

A reflexão da relevância do conhecimento do quanto um projeto de design influencia nas relações do homem com o espaço, e até mesmo com a sociedade e seus direitos constitucionais, é uma questão que deve fazer cada vez mais parte do cotidiano do profissional da área. Apesar de todos os entraves causados por um projeto que não contempla essa gama da população, existe um que é difícil de lidar, e por mais que o profissional tente é impossível sentir em sua totalidade até mesmo se colocando no lugar do outro com simulações ou técnicas do gênero; trata-se de um problema latente na sociedade que nada mais é que um reflexo das concepções de mundo que as pessoas criaram no decorrer da vida: o preconceito. 


\section{Preconceito: Termo "deficiência" e seus obstáculos na inclusão social}

Como explanado no tópico anterior o modo de como é realizada a inclusão social é tão importante quanto o resultado em si, dessa forma, o processo é uma ação complexa, necessariamente coletiva, global e não especial; é uma prática resultante de uma série de atitudes que vem de uma sociedade que deve se mostrar aberta a ver o próximo, entendê-lo e incluí-lo. É preciso mudar essa concepção do diferente e, assim como menciona Corrêa (2008), se trata de fazer das diferenças algo natural e valorizado e, ainda segundo a autora (2008, p. 93): "Práticas inclusivas significam abrir oportunidades iguais, trabalhar em um espaço que seja comum e compartilhado. A questão que fica é saber se conseguiremos colocar as práticas inclusivas em evidência para nossas vidas".

Apesar disso, a maneira que a deficiência é encarada tem evoluído ao longo dos anos, como coloca Simões e Bispo (2006, p. 26): "São diversos os modelos de análise/definição do que é a deficiência. Resultantes da evolução social e científica, os vários modelos podem coexistir temporalmente, mas haverá sempre aquele que é dominante em determinada época ou região geográfica". Os autores dissertam acerca dos três modelos que consideram principais para entender essas diferentes concepções de "deficiência" propostas por elas, sendo estes o: modelo moral e religioso, modelo médico e o modelo social.

Segundo o modelo religioso ou moral, a deficiência seria consequência de um castigo divino, e as pessoas com algum tipo de deficiência, seja ela física ou cognitiva, eram consideradas impuras, pois sua família deveria ter praticado algo que implicou nessa punição pré-determinada (SIMÕES e BISPO, 2006). Tal modelo de entendimento da deficiência, acaba por levar o indivíduo a se isolar de sua convivência em sociedade, além do sentimento de vergonha, que levam a atitudes como de auto exclusão além da baixa autoestima. Já o modelo médico condiciona toda a situação de deficiência a uma doença, modelo este veio associado ao desenvolvimento da medicina "moderna" no séc. XIX, na tentativa de salientar o papel da medicina na sociedade, ligando a questão como um problema técnico da medicina (SIMÕES e BISPO, 2006). Este modelo desconsiderava a possibilidade de adequação dos ambientes e produtos aos que detinham essas limitações, pois, por ser considerada uma doença, a única solução considerada era a cura da mesma, e não a adaptação do meio para uma melhor convivência desses indivíduos em sociedade.

O modelo social, por sua vez, tem a deficiência uma consequência de barreiras ambientes e atitudes da maioria, neste, é quando surge o reconhecimento do direito da participação de pessoas com deficiência de maneira democrática e justa, que garanta oportunidades iguais, que, segundo Simões e Bispo (2006) se opõem ao assistencialismo e à caridade que os modelos anteriormente colocados resultam. Dessa forma, a proposta do design inclusivo se baseia no que o modelo social propõe, pois é necessário analisar tais características não como incapacidades do usuário, mas sim como diferenças funcionais, focado sempre em suas habilidades no momento que se desenvolve o projeto, buscando proporcionar independência e liberdade a aqueles que fazem, ou podem vir a fazer, uso do espaço ou os elementos que o compõem.

Muitas das atitudes negativas face à deficiência, que ainda hoje persistem, têm por base os modelos moral e médico pois, tal como já foi referido anteriormente, a coexistência dos diversos modelos é possível, e em alguns sectores sociais, como por exemplo, em parte da classe médica ou dos media, a predominância do modelo social não é efectiva, levando a que as atitudes negativas e os preconceitos face às pessoas com deficiência, ainda perdurem. (SIMÕES; BISPO, 2006, p. 28 grifo nosso). 
É possível, desta forma, aproximar-se do entendimento que pensamentos preconceituosos influenciaram em toda a construção do que hoje constitui uma das piores barreiras que esses indivíduos se deparam todos os dias, uma barreira intangível, mas igualmente prejudicial no que se refere à convivência plena em sociedade. A exclusão social vem de diversas maneiras, de forma externa e de forma interna; e fazem disso um problema geral, pois são entraves construídos por toda uma sociedade que dificilmente se propõe a encarar situações por outras perspectivas que não a delas mesmas. Os modelos mais fechados perduram até hoje e é possível notá-lo desde as atitudes mais evidentes das pessoas, até a ação de desconsiderar aquela parcela da sociedade que foi condicionada a uma situação sem poder fazer nada a respeito. Lidar com essas limitações de forma justa, é repensar a concepção de deficiência, repensar o seu papel como profissional, e principalmente repensar seu papel como cidadão.

[...] é preciso ressaltar que a inclusão é um processo muito mais amplo que diz respeito a uma mudança de olhar sobre o mundo, sobre as relações sobre direitos; a inclusão diz respeito à percepção interna de cada indivíduo. A diversidade passa a ser vista como valor. A sociedade se modifica e a pessoa com deficiência também, para que todos possam conviver em condições de equiparação de oportunidades. A inclusão, portanto, é uma via de mão dupla (CAMBIAGHI, 2012, p. 32).

A palavra-chave para todo o conceito que circunda a inclusão, e até mesmo o design inclusivo propriamente dito, é a empatia. O designer como construtor de elementos de interação, seja ele um ambiente ou produto, deve buscar sempre compreender e olhar através da perspectiva de quem irá usá-lo, dessa forma, o conceito de design inclusivo deve fazer parte de toda a construção deste profissional. Mudar essa visão e ampliar a reflexão quanto a influência dessas relações dentro de um projeto é o primeiro passo para a fomentação da abordagem inclusiva na presente geração de designers, assim, adequar cada vez mais o que se cria aos que justificaram a criação, e não o inverso.

De fato, temos de trabalhar para reduzir os conflitos ao invés de escondê-los. Devemos ser capazes de nos reconhecermos, um na pele do outro e, mesmo assim, de nos sentirmos felizes porque ambos estão bem - o eu e o outro. Por práticas inclusivas, temos de reverter tal imagem da vantagem incondicional de uns sob os outros. Devemos ter em mente que, melhor do que sair ganhando sempre é ganhar sem riscos, pois tudo foi dividido justamente. Não é nem mesmo o fato de ganhar que importa e, sim, de se estar envolvido na construção de algo em conjunto que é bom para todos. A prática inclusiva é o processo de valorizar um indivíduo para que a riqueza por sua diversidade seja também a riqueza do grupo (CORRÊA, 2008, p. 93 grifo nosso).

Corrêa (2008) conclui sua colocação dissertando acerca dos efeitos da separação do que "é adequado para quem", e o que de fato se configura o processo de inclusão ao colocar que:

\footnotetext{
Quando começamos a pensar na diferença que nos separa como pessoas, talvez o processo de preparação para que sempre possamos incluir habilidades distintas em nosso meio fique mais forte como um elo que nos prende, ao invés de simplesmente rotularmos tais diferenças. Rotular significa termos de identificar quem é e quem não é, de modo que alguma pessoa possa ser contemplada com alguma vantagem. As práticas inclusivas não existem onde são feitos rótulos como referência de justiça. Não podemos falar de "inclusão de..." pessoas com deficiência ou do idoso, porque a partir do momento em que fizermos isso, já estaremos segregando. Segregar significa caracterizar, definir, separar. Temos de falar de inclusão como sendo um processo de todos para todos (CORRÊA, 2008, p. 94, grifo nosso).
}

Entende-se, portanto, que o processo de inclusão social é complexo e condicionado a atitudes da sociedade em si e também aos atores envolvidos da construção dos meios externos em 
que as interações sociais ocorrem, ambientes construídos e produtos que o compõem, por exemplo. O design inclusivo apesar de não ter normas e padrões que o guiem no momento que se propõem soluções de projeto, este é auxiliado pelas tecnologias assistivas, o que em certos momentos é tratado como "design assistivo", que pode ter diversas naturezas dentro desta área de conhecimento: produtos, metodologias de análise, ambientes, etc. Contudo, todas as vertentes dessa tecnologia tratam-se de medidas que visam de forma comum a inclusão social de pessoas com alguma variação funcional, para que promova no ambiente ou convivência com ele (por meio de produtos), um local mais funcional, confortável e seguro para todos.

O uso do termo "tecnologia assistiva" foi usado devido sua vasta significação no que concerne a possibilidade de busca por essa inclusão, pois para Damasceno $(2002$, p. 1) esta se trata de: "[...] toda e qualquer ferramenta ou recurso utilizado com a finalidade de proporcionar uma maior independência e autonomia à pessoa com deficiência".

A questão inclusiva aplicada ao design, e as ferramentas que proporcionam tal conceito nos projetos, é uma necessidade latente, de modo que garante direitos que todo cidadão tem como seu, que acaba por sendo comprometido pela falta de acessibilidade e estudo dessas necessida des em lugares nos quais essas aplicações mostram-se de grande importância. Nesse sentido, é imprescindível que se constitua da fase inicial de qualquer projeto entender essas demandas, ou seja, deve haver a organização de requisitos de projeto onde haja a integração desses diversos perfis de usuários que poderão vir a utilizar o produto e/ou ambiente projetado. Pereira (2017, p. 43) afirma que o design inclusivo nada mais é que o design na sua forma mais ampla, com seu público diversificado que requer requisitos de projeto cada vez mais ampliados, trazendo à tona a necessidade de pesquisas extensas e maior gama de repertório no momento de sua construção, desde seu projeto conceitual até sua concepção propriamente dita. Assim, como coloca Boff (1998, p. 9): "todo ponto de vista é a vista de um ponto. Para entender como alguém lê, é necessário saber como são seus olhos e qual é a sua visão do mundo"; o designer deve buscar conhecer casos isolados, problemáticas pontuais de forma a enriquecer a visão do todo. Por mais que um projeto que atenda as necessidades de cem por cento da população mundial seja, de certa forma, uma utopia, para Pereira (2017, p. 44) as soluções de design devem ser especialistas e ao mesmo tempo generalistas, pois:

Especialistas porque consideram uma forma de uso específica, uma habilidade oriunda da diferença funcional, ou seja, da necessidade ou da limitação peculiar de um grupo menor, que pode ser em algum momento da vida também de um grupo maior. Generalistas porque abarcam um vasto campo de possibilidades de uso e de contextos (PEREIRA, 2017, P.44).

Por fim, tais reflexões salientam ainda mais a importância da multidisciplinaridade no design e como esta enriquece as análises e recomendações no processo de criação. A discussão do que é inclusão social, também é de suma importância no momento em que se estabelecem os requisitos de projeto, de modo a se aproximar cada vez mais daquele que vem a usar um produto projetado e tem como direito o ir e vir. Parte-se do pressuposto de que é um processo de solucionar os problemas de fato, e evidenciar o poder que o entender o próximo faz a uma sociedade que se constrói a cada dia. 


\section{Referências}

ASSOCIAÇÃO BRASILEIRA DE NORMAS TÉCNICAS: NBR 14022. Acessibilidade em Veículos de Características Urbanas para o Transporte Coletivo de Passagerios. Rio de Janeiro, 2011.

BAPTISTA, Arthur. Critérios para uma teoria da acessibilidade efetiva. In: Um novo olhar para o projeto: a ergonomia no ambiente construído/organização Claudia Mont'Alvão e Vilma Villarouco. Teresópolis-RJ: 2AB, 2011.

BATISTA, Marcus Welby; ENUMO, Sônia Regina Fiorim. Inclusão escolar e deficiência mental: análise da interação social entre companheiros. Espiríto Santo: Estudos de Psicologia, 2004.

BOFF, Leonardo. A águia e a galinha: uma metáfora da condição humana. Rio de Janeiro: Editora Vozes, 1998.

BISPO, Renato; SIMÕES, Jorge Falcato. Design Inclusivo: Acessibilidade e Usabilidade em Produtos, Serviços e Ambientes. 2aㅡ ed, Lisboa: Centro Português de Design, 2006.

CAMBIAGHI, Silvana. Desenho Universal: Métodos e técnicas para arquitetos e urbanistas. São Paulo: SENAC, 2011.

CARLETTO, Ana Claudia; CAMBIAGHI, Silvana. Desenho Universal: um conceito para todos. São Paulo, 2008.

COLEMAN, R. et al. What is inclusive design? Disponível em < http://www.inclusivedesigntoolkit.com/betterdesign2/whatis/whatis.html> Acesso em 20 de junho de 2018.

CORRÊA, Rosa Maria. Avanços e desafios na construção de uma sociedade inclusiva. Belo Horizonte-MG. Sociedade Inclusiva: PUC-MG, 2008.

MIRANDA, Cristiana; SILVA, Caio Márcio Almeida e; OKIMOTO, Maria Lucia Leite Ribeiro. Notas acerca da acessibilidade ao sistema de transporte público de Curitiba: O caso da plataforma elevatória da Estação-Tubo. Paraná. Ação Ergonômica: Revista Brasileira de Ergonomia, v. 7 n. 3, 2012.

PEREIRA, Danila Gomes. A aplicabilidade do design inclusivo em projetos de design. Danila Gomes Pereira: orientador: Manuela Quaresma. Dissertação (mestrado) - Pontifícia Universidade Católica do Rio de Janeiro, Departamento de Artes e Design, 2017. 